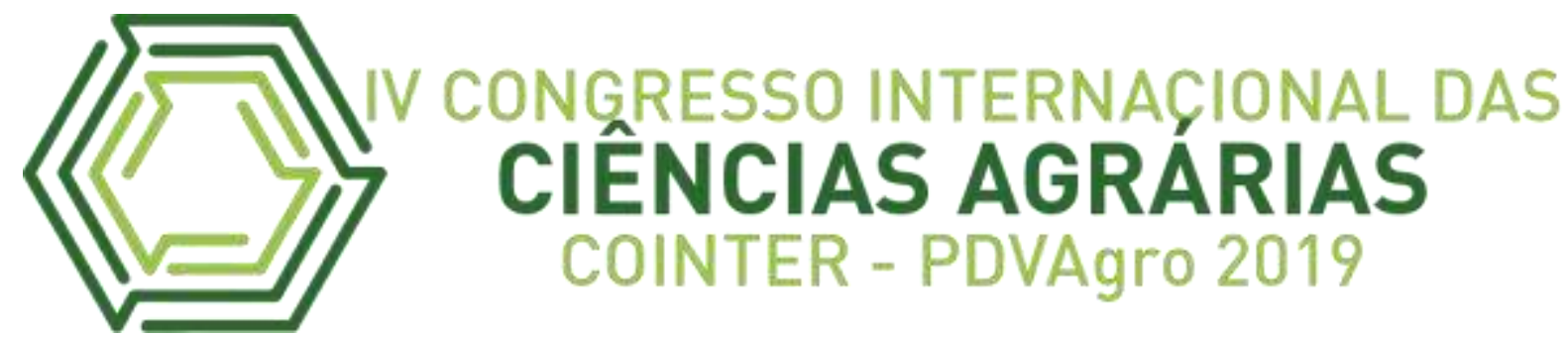

\title{
ANÁLISE ESPAÇO-TEMPORAL DA ÁREA PLANTADA E PRODUÇÃO DE SOJA DA MICRORREGIÃO DE PARAGOMINAS, SUDESTE DO PARÁ
}

\section{ANÁLISIS ESPACIO-TEMPORAL DEL ÁREA PLANTADA Y PRODUCCIÓN DE SOJA DE LA MICRORREGIÓN DE PARAGOMINAS, SURESTE DEL PARÁ}

\author{
SPATIOTEMPORAL ANALYSIS OF PLANTED AREA AND SOYBEAN \\ PRODUCTION OF PARAGOMINAS MICROREGION, SOUTHEAST OF PARÁ
}

\author{
Apresentação: Comunicação Oral \\ Luã Souza de Oliveira ${ }^{1}$; Antonio Jean Mota de Lima²; Marluce Reis Souza Santa Brígida ${ }^{3}$; \\ Wanderson Cunha Pereira ${ }^{4}$; Gutierre Pereira $\mathrm{Maciel}^{5}$
}

DOI: https://doi.org/10.31692/2526-7701.IVCOINTERPDVAgro.2019.0024

\begin{abstract}
Resumo
A soja é uma cultura agrícola que desempenha grande papel social e econômico para o Brasil, devido sua cadeia produtiva, desde a semeadura até a comercialização, contribuir para geração de vários postos de trabalho, renda e também divisas, estas pela exportação do produto para o mercado internacional. Este estudo teve como objetivo analisar a evolução espaço-temporal da área plantada e produção de soja da microrregião de Paragominas, Sudeste Paraense, no período de 2002 a 2017. Os dados foram obtidos no Instituto Brasileiro de Geografia e Estatística (IBGE) que, através da plataforma Sistema IBGE de recuperação Automática (SIDRA), disponibiliza dados da produção agrícola. Os gráficos de evolução temporal e evolução espaço-temporal foram gerados utilizando o programa Excel 2010 e QGIS (Quantum GIS, versão 3.8), respectivamente. Atualmente, a região Oeste do Brasil, onde predomina o bioma Cerrado, é a principal produtora de soja do país. Contudo, o cultivo de soja vem se deslocando cada vez mais sobre outras regiões, a exemplo do bioma Amazônia, no qual está inserido a microrregião de Paragominas. Vários fatores contribuem para a expansão da soja na Amazônia e estão intimamente relacionados a aspectos de solo, clima, logística e política. Em 2017, a área plantada com soja na microrregião de Paragominas foi de 302.740 ha, o que representa aumento de $16.089,3 \%$ em relação a 2002, quando foram plantados 1.870 ha, enquanto que para o mesmo período, a produção cresceu cerca de $56.817,1 \%$, saltou de 5.456 t para 1.064 .349 t. Destaca-se o município de Paragominas, único que apresentou, na safra agrícola de 2017, área plantada e produção superior a 100.000 ha e 400.000 t, respectivamente. A expansão vertiginosa
\end{abstract}

\footnotetext{
${ }^{1}$ Engenharia Florestal, Universidade Federal Rural da Amazônia (UFRA), souluasouza7@gmail.com

${ }^{2}$ Agronomia, Universidade Federal Rural da Amazônia (UFRA), jeantonheiro@hotmail.com

${ }^{3}$ Mestrado em Agriculturas Amazônicas, Universidade Federal do Pará (UFPA), Marluce_brigida@hotmail.com

${ }^{4}$ Mestrado em Estatística, Universidade Federal do Pará (UFPA), wanderson.pereira@ufra.edu.br

${ }^{5}$ Mestrado em Agronomia, Universidade Federal Rural da Amazônia (UFRA), gutierre_maciel@hotmail.com
} 
da soja na microrregião de Paragominas se deve, principalmente, a sua localização estratégica; incentivo governamental; condições de solo e clima ideais ao cultivo da cultura; desenvolvimento de cultivares para a região; e, disponibilidade de terras mais baratas.

Palavras-Chave: Fabaceae, geografia, geoprocessamento, economia regional.

\title{
Resumen
}

La soja es un cultivo agrícola que desempeña un importante papel social y económico para Brasil, debido a su cadena de producción, desde la siembra hasta la comercialización, contribuyendo a la generación de diversos empleos, ingresos y también divisas, exportando el producto al mercado internacional. Este estudio tuvo como objetivo analizar la evolución espacio-temporal del área plantada y de la producción de soja de la microrregión de Paragominas, Sureste do Pará, de 2002 a 2017. Los datos se obtuvieron del Instituto Brasileño de Geografía y Estadística (IBGE) que, a través de la plataforma del Sistema de Recuperación Automática IBGE (SRAI), proporciona datos sobre la producción agrícola. Se generaron los gráficos de evolución de tiempo y evolución de espacio-tiempo usando lo programa Excel 2010 y QGIS (Quantum GIS, versión 3.8), respectivamente. Actualmente, la región occidental de Brasil, donde predomina el bioma Cerrado, es la principal productora de soja en el país. Sin embargo, el cultivo de soja se ha estado moviendo cada vez más a otras regiones, como el bioma Amazónico, en el que se inserta la microrregión de Paragominas. Varios factores contribuyen a la expansión de la soja en la Amazonía y están estrechamente relacionados con el suelo, el clima, la logística y los aspectos políticos. En 2017, el área plantada con soja en la micorregión de Paragominas fue de 302,740 ha, lo que representa un aumento de 16,089.3\% en comparación con 2002, cuando se plantaron 1,870 ha, mientras que para el mismo período, la producción creció en 56,817.1\%, saltó de 5,456 t hasta 1,064,349 t. Destaca el municipio de Paragominas, el único que presentó, en la temporada agrícola 2017, área plantada y producción por encima de 100,000 ha y 400,000 t, respectivamente. La expansión vertiginosa de la soya en la microrregión de Paragominas se debe principalmente a su ubicación estratégica; incentivo del gobierno; condiciones ideales de suelo y clima para el cultivo; desarrollo de cultivares para la región; y, disponibilidad de tierra más barata.

Palabras Clave: Fabaceae, geografía, geoprocesamiento, economía regional.

\begin{abstract}
Soybean is an agricultural crop that plays a major social and economic role for Brazil, due to its production chain, from sowing to marketing, contributing to the generation of various jobs, income and also foreign exchange, these by exporting the product to the international market. This study aimed to analyze the spatiotemporal evolution of planted area and soybean production in the Paragominas microregion, Southeast of Pará, from 2002 to 2017. The data were obtained from the Brazilian Institute of Geography and Statistics (BIGE) which, through the IBGE Automatic Recovery System (IARS) platform, provides data on agricultural production. Time evolution and space-time evolution graphs were generated using Excel 2010 and QGIS (Quantum GIS, version 3.8), respectively. Currently, the western region of Brazil, where the Cerrado biome predominates, is the main soy producer in the country. However,
\end{abstract}


soybean cultivation has been moving more and more over other regions, such as the Amazon biome, in which the Paragominas microregion is inserted. Several factors contribute to the expansion of soybeans in the Amazon and are closely related to soil, climate, logistics and policy aspects. In 2017, the area planted with soybeans in Paragominas microrigion was 302,740 ha, representing an increase of $16,089.3 \%$ compared to 2002 , when 1,870 ha were planted, while in the same period, production grew 56,817.1\%, jumped from 5,456 t to $1,064,349$ t. The municipality of Paragominas stands out, the only one that presented, in the 2017 agricultural season, planted area and production above 100,000 ha and 400,000 t, respectively. The vertiginous expansion of soybeans in the Paragominas microregion is mainly due to its strategic location; government incentive; ideal soil and climate conditions for crop cultivation; development of cultivars for the region; and, availability of cheaper land.

Keywords: Fabaceae, geography, geoprocessing, regional economy.

\section{Introdução}

A cultura da soja (Glycine max (L.) Merr.), pertencente à família Fabaceae, tem um grande papel no cenário da economia brasileira (FERREIRA, 2011), pois sua cadeia produtiva gera vários postos de trabalho, renda e divisas, estas pela venda do grão no mercado internacional (BERTRAND; CADIER; GASQUÈS, 2005; FREITAS, 2011).

Atualmente, a leguminosa, principal commodity mundial, dá origem a vários subprodutos, dentre eles o farelo e óleo vegetal, bastante utilizados na nutrição animal e alimentação humana, respectivamente (CRUZ et al., 2016; SANCHES; MICHELLON; ROESSING, 2004; SILVA et al., 2006).

No Brasil, o cultivo de soja vem se deslocando cada vez mais das regiões Sul e Sudeste para outras áreas, a exemplo da região Norte (COSTA, 2000; FREITAS, 2011). A chegada dessa cultura implica algumas alterações na economia e paisagem local, através de todo o suporte que a atividade necessita, tais como: instalação de empresas multinacionais, indústrias de grãos, infraestrutura, etc (OLIVEIRA, 2015).

A geotecnologia possibilita, através do processamento de dados e informações geográficas, estudar a dinâmica da expansão de uma atividade econômica em determinada região, com baixo custo de instalação e maior velocidade na obtenção dos dados (CASTANHO; TEODORO, 2010; MOTTA; FONTANA; WEBER, 2003; ROSA, 2011). Essa vantagem torna o desenvolvimento e aplicação de pesquisas geoespaciais mais eficientes no estudo e, principalmente, interpretação dos resultados obtidos.

Os mapas gerados por essa ferramenta podem contribuir para um planejamento rural 
mais adequado, porque oferece uma visão mais ampla da dinâmica da atividade agrícola (MACIEL et al., 2018). Mudanças no uso e ocupação do solo têm reflexos sobre a economia regional e, por isso, devem ser estudas a fim de compreender suas causas e consequências.

Estudos nesse sentido auxiliam na identificação de áreas favoráveis e desfavoráveis ao investimento tanto privado quanto público, corroborando, assim, para uma melhor gestão dos recursos destinados ao setor de grãos na região.

Diante do exposto, este trabalho tem como objetivo analisar espacial e temporalmente a dinâmica da área plantada e produção de soja da microrregião de Paragominas, Sudeste Paraense, no período de 2002 a 2017.

\section{Fundamentação Teórica}

A cultura da soja, embora amplamente difundida no Brasil (SANTOS et al., 2008), continua avançando sobre regiões antes consideradas inviáveis ao seu cultivo, a exemplo da Amazônia que, atualmente, representa a principal fronteira agrícola de grãos do país, sendo fundamental para o crescimento do setor (COSTA, 2015).

A partir da década de 90, quando houve grande interesse de empresas do complexo industrial da soja em conquistar novas terras na Amazônia, com o claro objetivo de diminuir o custo com o escoamento produção destinado à exportação, surgiram sub-regiões, dentre as quais algumas viraram nova fronteira agrícola da soja (FLEXOR; LEAO; LIMA, 2006), como é caso das regiões Oeste e Sudeste do Pará.

Os fatores principais que corroboram para a expansão do cultivo da soja na Amazônia referem-se, dentre outros aspectos, à presença, em determinados locais, de terras agricultáveis com menor custo; posição privilegiada em relação ao escoamento da produção; relevo adequado; solo e clima favoráveis ao cultivo (FARIAS; NEPOMUCENO; NEUMAIER, 2007), com luz intensa e água abundante.

Além disso, o desenvolvimento de pesquisas de melhoramento genético ajudou a lançar cultivares adaptadas às condições edafoclimáticas da região amazônica, processo este que foi crucial também na expansão da soja no Brasil, inclusive no Cerrado (SOUSA, 1990; TANAKA; MASCARENHAS; BORKET, 1993; BARROS et al., 2003; EMBRAPA SOJA, 2003; KIIHL; GARCIA, 1989).

Outro fator importe diz respeito aos incentivos do Estado, que beneficiam o produtor pela concessão de créditos e favorecem a instalação de empresas e indústrias na região, bem 
como a implantação de infraestrutura que, através de rodovias estratégicas e sistemas de transporte intermodais, facilitam o escoamento da produção (FLEXOR; LEAO; LIMA, 2006).

De acordo com Fukui e Lopes (2019), o sistema de transporte brasileiro apresenta vários problemas que freiam o crescimento do setor de produção de grãos: estradas não conservadas; modal rodoviário predominante; e elevada distância entre os principais centros produtores e os portos brasileiros. Logo, as regiões que possuem melhor infraestrutura e/ou que estejam bem localizadas, serão prioridades de investimentos.

A área plantada de soja na região Norte, que representa a maior parte da Amazônia nacional, cresceu cerca de $1.084 \%$ de 2002 a 2017 (IBGE, 2018), comportando-se como região válvula de escape para o cultivo da oleaginosa. Isso demonstra, ainda, que o bioma tem grande potencial para o pleno desenvolvimento da cultura e de sua cadeia produtiva, do ponto de vista edáfico, climático, logístico e político (COSTA, 2015).

Além da área plantada, a produção de soja é também produto direto da produtividade da lavoura. O crescimento da sojicultura e de seu rendimento pode alcançar patamares elevados de diversas formas, mas principalmente pela adoção de técnicas de cultivo atuais e tecnologias sofisticadas, como: cultivares mais produtivas, resistentes a patógenos, e adaptadas ao clima e solo local; uso de máquinas e implementos para operações de semeadura, colheita e pulverização de defensivos agrícolas; sementes certificadas; e, inserção de processos automatizados, que sigam a filosofia da agricultura de precisão (FREITAS, 2011; FERREIRA, 2011; FUKUI; LOPES, 2019).

Em 2017, o estado do Pará, com área plantada de 500.385 ha, apresentou produção de 1.632.115 t, de modo que 85,16\% correspondeu a mesorregião Sudeste Paraense (IBGE 2018), a qual possui a microrregião de Paragominas como principal polo produtor. Nos últimos anos, o estado paraense ganhou atenção do setor de grãos não apenas pela expansão relevante do plantio de soja, mas principalmente pela velocidade com que o processo acontece (BENATTI, 2003; NINNI, 2004; SCHLESINGER; NORONHA, 2006).

De acordo com o IBGE (2018), na safra 2017, a microrregião de Paragominas apresentou área plantada de 302.740 ha e produção de 1.064 .349 t, que resultou em produtividade média de $3,516 \mathrm{t} \mathrm{ha}^{-1}$, superior aos rendimentos médios da mesorregião Sudeste Paraense $\left(3,320 \mathrm{t} \mathrm{ha}^{-1}\right)$, do Pará $\left(3,262 \mathrm{t} \mathrm{ha}^{-1}\right)$ e do Brasil $\left(3,377 \mathrm{t} \mathrm{ha}^{-1}\right)$.

Costa (2000) relata que a produção de grãos vem incorporando várias áreas do polo Paragominas ao processo produtivo, revelando-se uma opção melhor de renda, principalmente 
para os madeireiros da região, que enfrentam barreiras na obtenção da madeira. De modo geral, essas áreas incorporadas são principalmente áreas de pastagens degradadas. El-Husny et al. (2006) estima que na região do polo Paragominas existam 500 mil hectares de pastagens degradadas em relevo suavemente ondulado, favoráveis ao cultivo mecanizado da soja.

\section{Metodologia}

A área de estudo do trabalho foi a microrregião de Paragominas (Figura 1), a qual está localizada na mesorregião Sudeste Paraense. A microrregião é constituída pelos seguintes municípios: Abel Figueiredo, Bom Jesus do Tocantins, Dom Eliseu, Goianésia, Paragominas, Rondon do Pará e Ulianópolis.

Os dados referentes à área plantada, em hectares (ha), e produção de soja, em toneladas (t), no período de 2002 a 2017, foram adquiridos na plataforma digital do Instituto Brasileiro de Geografia e Estatística (IBGE), mediante acesso ao Sistema IBGE de recuperação automática (SIDRA), que possui informações quantitativas da Produção Agrícola Municipal (PAM).

Figura 1. Mapa de localização da microrregião de Paragominas, Sudeste Paraense.

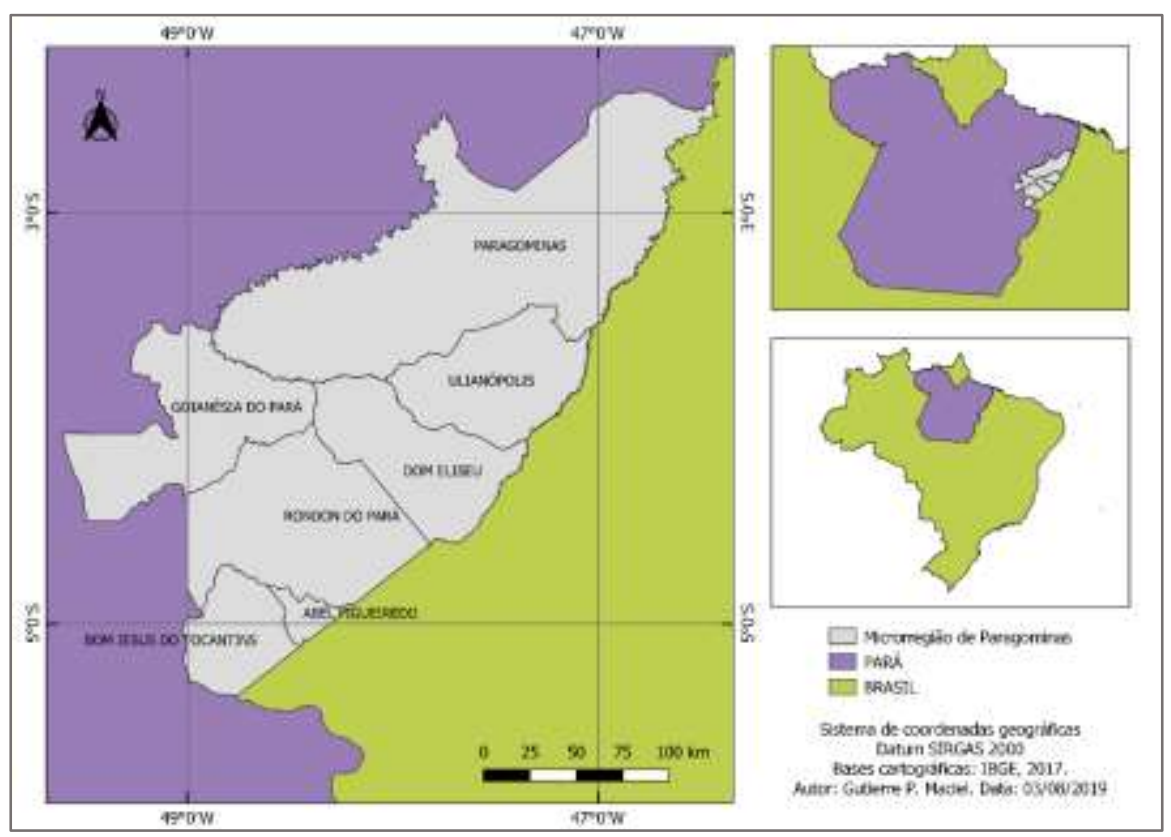

Fonte: Própria (2019).

Os dados não sofreram nenhuma conversão de unidade. Todos os municípios que constituem a área de estudo apresentaram valores de área plantada e produção, os quais não foram constatados em alguns anos do período avaliado. Para estes casos, adotou-se o valor zero.

Com auxílio do software Excel 2010, as informações foram organizadas em planilha 
eletrônica, para confecção do gráfico. Para o geoprocessamento dos dados e elaboração dos mapas referentes à área plantada e produção de soja, nos anos de 2002, 2007, 2012 e 2017, utilizou-se o programa computacional Quantum GIS (versão 3.8). Esses anos específicos foram escolhidos por representarem bem a dinâmica sojicultura no intervalo de tempo estudado, o que é essencial na identificação de contrastes.

Os dados foram divididos e alocados em classes: área plantada $(0 ; 1-5.000 ; 5.000-$ 50.000; 50.000-100.000; > 100.000), em hectares; e produção (0; 1-10.000; 10.000-100.000; 100.000-400.000; > 400.000), em toneladas. Para cada classe, atribui-se uma tonalidade de cor, mais clara para valores baixos e mais escura à medida que os valores aumentam.

A metodologia deste estudo baseou-se nos trabalhos de Souza et al. (2009) e Maciel et al. (2018), que objetivaram avaliar e detectar padrões espaço-temporais na cafeicultura e na cultura do feijão-caupi, respectivamente.

\section{Resultados e Discussão}

Na microrregião de Paragominas, de 2002 a 2017, houve incrementos bastante significativos na cultura da soja, tanto para área plantada quanto para produção (Figura 2). Em 2017, a área plantada foi de 302.740 ha, o que representa aumento de 16.089,3 \% em relação a 2002, quando foram plantados 1.870 ha, enquanto que para o mesmo período, a produção cresceu cerca de $56.817,1 \%$, saltou de $5.456 \mathrm{t}$ para $1.064 .349 \mathrm{t}$.

Figura 2. Evolução temporal da área plantada e produção de soja da microrregião de Paragominas, 2002-2017.

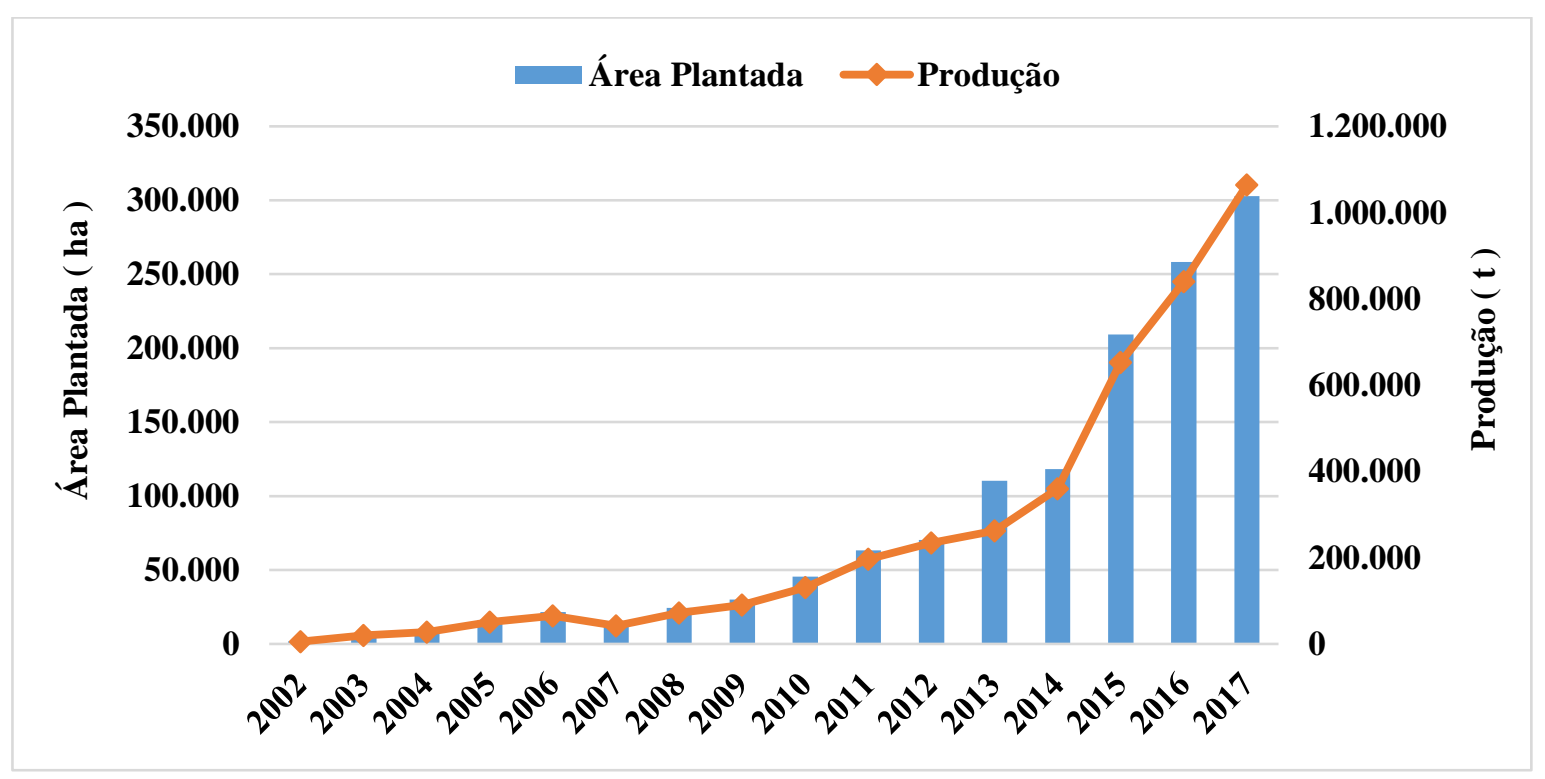

Nos últimos anos, a expansão do plantio de soja na microrregião de Paragominas 
avançou na maioria dos munícipios, com destaque para os municípios de Paragominas e Dom Eliseu, que ultrapassaram os 50.000 e 100.000 ha de área plantada, respectivamente (Figuras 3, 4, 5 e 6). Esse crescimento pode estar associado a diversos fatores, dentre eles edáficos, climáticos, logísticos e políticos, os quais acabam incentivando o plantio de soja na microrregião.

Rodrigues et al. (1999) revela que as condições de clima, topografia e solos do polo Paragominas são propícias ao cultivo da leguminosa. Ainda segundo o autor, Dom Eliseu e Paragominas, são favorecidos por terem relevo plano ou suavemente ondulados, aspectos fundamentais para a mecanização da atividade, do preparo da terra à colheita.

Figura 3. Área Plantada - 2002

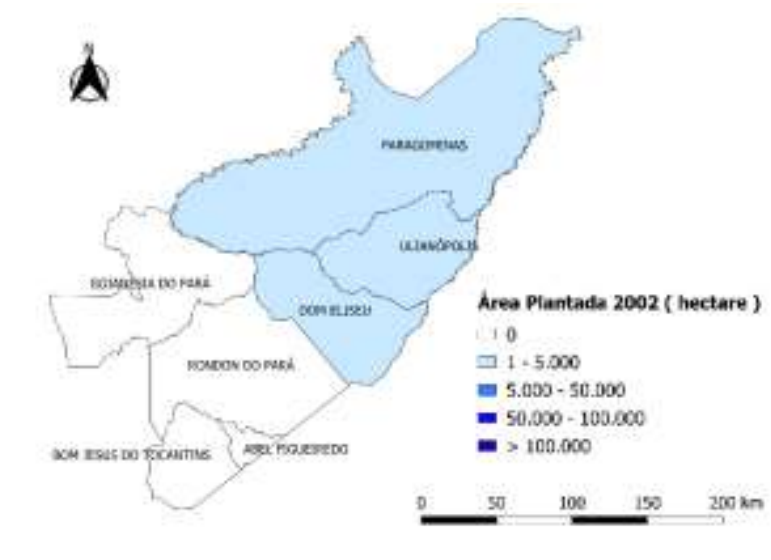

Figura 4. Área Plantada - 2007

Figura 5. Área Plantada - 2012
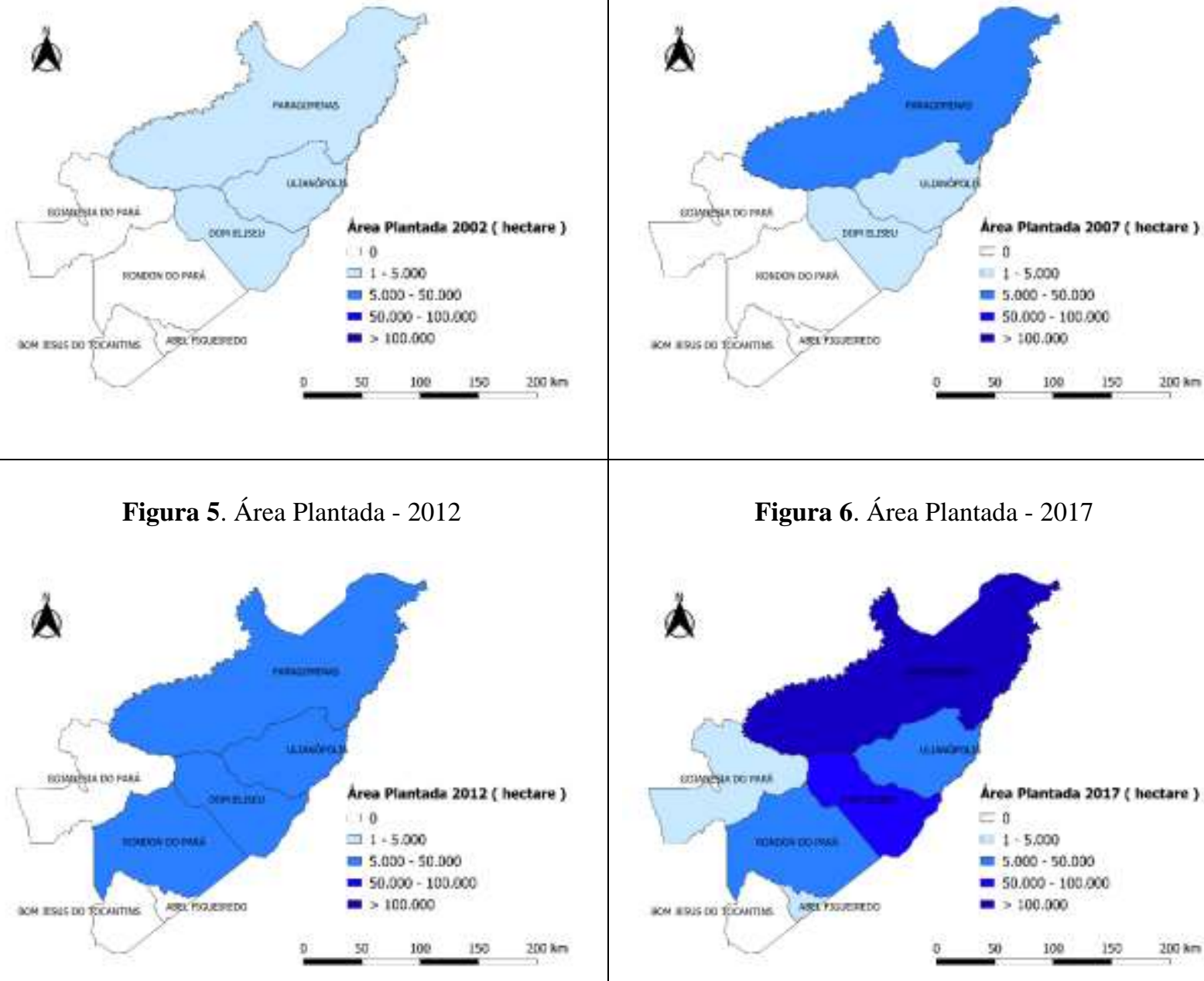

Figura 6. Área Plantada - 2017

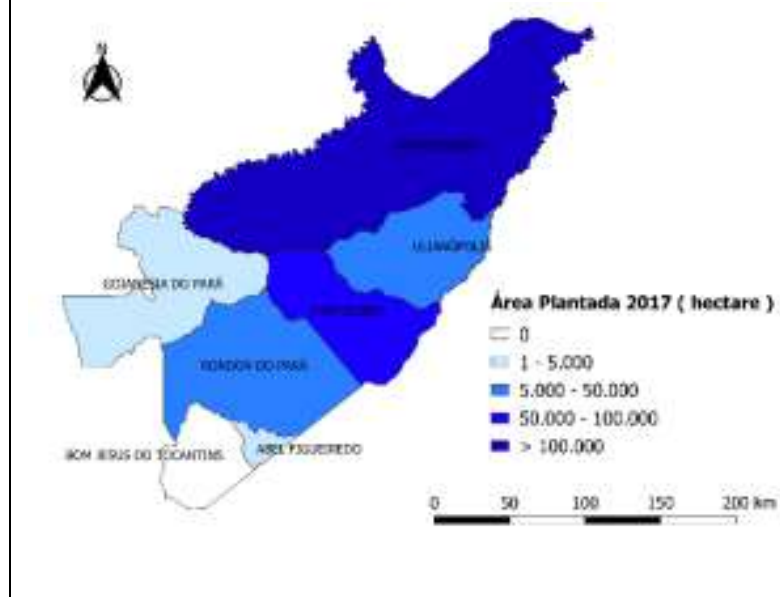

O governo do Pará, desde o final da década de 90, através de políticas agrícolas, vem incentivando o plantio de soja na microrregião, elegendo a leguminosa como prioritária, frente 
a outros grãos como milho e arroz (EL-HUSNY et al., 2003), o que muito corroborou para o aumento da área plantada na região.

Ainda do ponto de vista político, ressalta-se também a concessão de créditos por parte do governo aos produtores, que preferem investir em um setor em plena ascensão, caso da sojicultura, em detrimento de setores pioneiros, isto é, com mais tradição na região, como o pecuário e o madeireiro (CABRAL; GOMES, 2013).

Outro fator que contribuiu para o avanço da soja na região diz respeito ao apoio logístico, visto que a rodovia Belém-Brasília (BR-010) passa pelos principais municípios produtores, Paragominas e Dom Eliseu, e permite melhor acesso a hidrovia Tocantins e a ferrovia Carajás (COSTA, 2000).

Para Fearnside (2005), a expansão do cultivo da soja é bastante estimulada pela infraestrutura local. Dessa forma, a infraestrutura da microrregião de Paragominas associada à sua posição estratégica, proporciona ao produtor um escoamento mais ágil da produção de soja, além de diminuir os custos com o transporte da carga.

Analisando a evolução espacial da produção de soja da microrregião de Paragominas, verificou-se que a maioria dos municípios aumentaram sua produção, especialmente Paragominas que, em 2017, produziu mais de 400.000 t do grão (Figuras 7, 8, 9 e 10). Conforme Alves (2014), o município de Paragominas desenvolve uma agricultura que se destaca dentre os demais da região, pelo aparelhamento das propriedades, que utilizam alto nível tecnológico.

O aumento da produção observado na microrregião está diretamente relacionado ao aumento da área plantada. Costa (2012), estudando a produção agrícola entre 1997 a 2010, observou que o crescimento do cultivo da soja no estado do Pará aumentou devido a incorporação de novas áreas.

Infere-se que esse incremento de novas áreas se deu, provavelmente, pela conversão de pastagens degradadas em plantios de soja. El-Husny et al. (2006) estima que no município de Paragominas existam 500 mil hectares de pastagens degradadas em relevo suavemente ondulado, favoráveis ao cultivo dessa oleaginosa.

Por outro lado, o crescimento significativo da produção observado pode ser atribuído também à produtividade. De acordo com o IBGE (2018), a produtividade da microrregião de Paragominas foi de 3,516 t ha ${ }^{-1}$ em 2017, maior que os rendimentos médios da mesorregião Sudeste Paraense, do Pará e do Brasil, indicando que os sistemas de plantio e métodos de 
manejo são sofisticados.

Figura 7. Produção - 2002

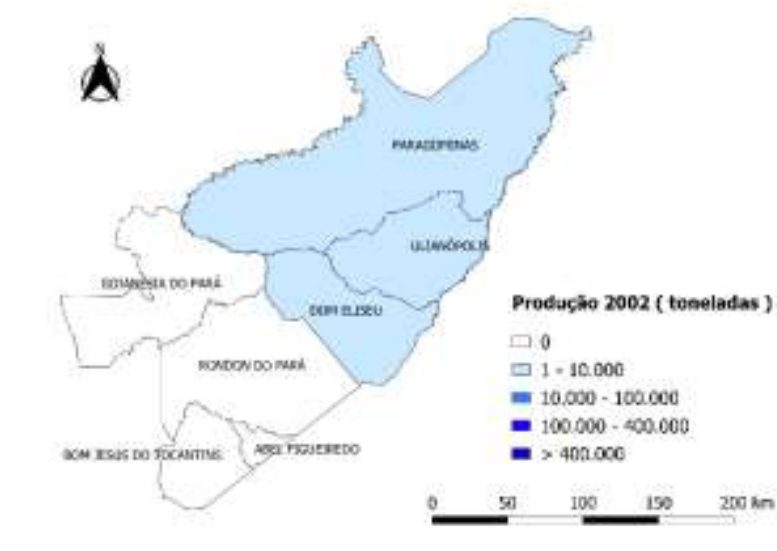

Figura 9. Produção - 2012

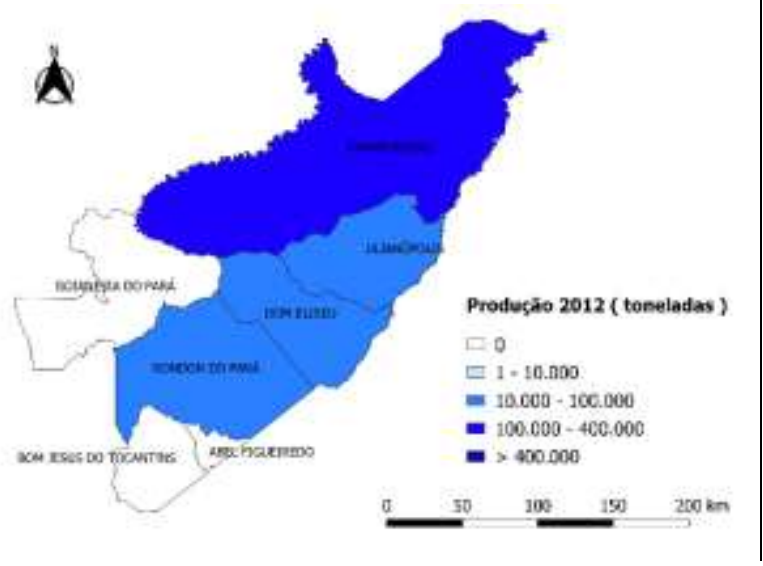

Figura 8. Produção - 2007

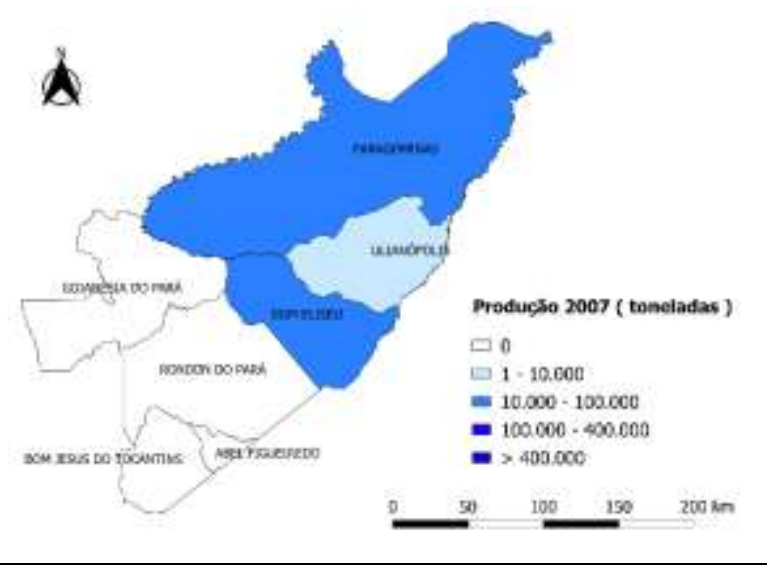

Figura 10. Produção - 2017

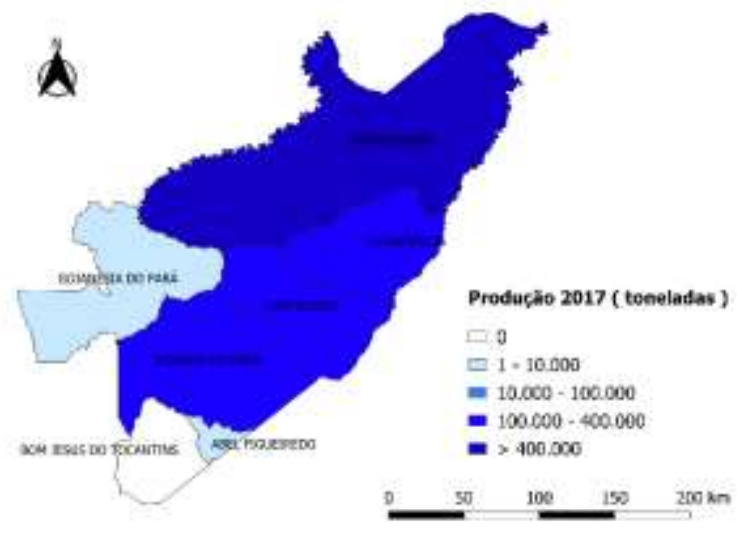

Ferreira (2011) relatou que o crescimento da produtividade brasileira de soja, de 1.025 $\mathrm{kg} \mathrm{ha}^{-1}$ para $2.670 \mathrm{~kg} \mathrm{ha}^{-1}$, entre a safras 1970/1971 e 2008/09, foi resultado de avanços tecnológicos. À medida que o produtor rural faz o uso de técnicas e tecnologias mais sofisticadas de produção, como por exemplo, cultivares mais adaptadas, com maior potencial produtivo e mais resistentes ao ataque de pragas e doenças, a produtividade da lavoura tende a aumentar de forma considerável.

EL-Husny et al. (2006), avaliando o comportamento de algumas linhagens de soja, recomendou para o polo de Paragominas as cultivares BRS Tracajá, BRS Sambaíba e BRS babaçu e BRS Seridó RCH, as duas primeiras com produtividade superior a $3.800 \mathrm{~kg} \mathrm{ha}^{-1}$. Contudo, para que a planta atinja esse potencial produtivo, é necessário que o nível de fertilidade do solo esteja adequado, o que pode ser resolvido com a correção da acidez e adubação equilibrada. 


\section{Conclusões}

A cultura da soja cresceu vertiginosamente na microrregião de Paragominas nos últimos anos, tanto em relação à área plantada quanto produção. Dentre os fatores que contribuíram para a expansão da leguminosa, os principais foram: terras mais baratas, o que diminui o custo de implantação do cultivo; localização geográfica estratégica, próxima de rodovias (BR-010) e hidrovias (rio Tocantins) importantes, beneficiando a logística do escoamento da produção; e, desenvolvimento de cultivares produtivas e adaptadas às condições edafoclimáticas da região, que favorece o aumento do rendimento.

Outro fator relevante que corroborou para o atual cenário, refere-se ao incentivo governamental, desde o apoio para o desenvolvimento de cultivares adaptadas à região até a concessão de créditos aos produtores.

A microrregião de Paragominas evidencia, a partir dos fatores supracitados, a sua elevada competitividade da região no setor de grãos, impondo-se como uma das principais fronteiras agrícolas da Amazônia.

O município de Paragominas foi o maior destaque da microrregião, apresentando a maior evolução de área plantada e produção de soja. Paragominas demonstra, ainda, elevado potencial para a expansão de soja, tendo em vista a grande disponibilidade de terras no município, principalmente pastagens degradadas, as quais podem ser convertidas em plantios de soja, como já vem acontecendo.

A geotecnologia, por meio do geoprocessamento dos dados, constituiu-se ferramenta bastante importante neste estudo, pois tornou a interpretação dos resultados mais clara e didática, o que muito corrobora para o direcionamento da gestão do setor produtivo de grãos na microrregião de Paragominas.

\section{Referências}

ALVES, R. W. L.; CARVALHO, M. J. E.; SILVA, T. G. L. Diagnóstico Agrícola do Município de Paragominas, PA. Embrapa Amazônia Oriental (Boletim, 91). Belém, Pará. 2014. 26 p. Disponível em: https://www.embrapa.br/amazonia-oriental/busca-de-publicacoes//publicacao/988380/diagnostico-agricola-do-municipio-de-paragominas-pa. Acessado em: 10 Ago 2019.

BARROS, H. B. et al. Efeito das épocas de semeadura no comportamento de cultivares de soja, no sul do estado de Tocantins. Revista Ceres, v. 50, n. 291, p. 565-572, 2003. 
BENATTI, J. H. A soja na Amazônia e o ordenamento territorial. In: SEMINÁRIO: A GEOPOLÍTICA DA SOJA NA AMAZÔNIA. Anais do Seminário Geopolítica da Soja na Amazônia. Belém, Museu Paraense Emílio Goeldi, 2003.

BERTRAND, J-P.; CADIER, C.; GASQUÈS, J. G. O crédito: fator essencial à expansão da soja em Mato Grosso. Cadernos de Ciência \& Tecnologia, v. 22, n. 1, p. 109-123, 2005.

CABRAL, E.; GOMES, S. Gestão ambiental pública em municípios com forte correlação entre desmatamento e expansão da pecuária, soja e madeira. Ensaios FEE, p. 167-194, 2013.

CASTANHO, R. B. TEODORO, M. A. O uso de geotecnologias no estudo da produção agropecuária. Brazilian Geographical Journal: Geosciences and Humanities Research Médium, v. 1, p. 136-153, 2010.

COSTA, F. G. Avaliação do Potencial de Expansão da Soja na Amazônia Legal: uma aplicação do modelo de Von Thünen. Piracicaba, 2000. 162 p. Dissertação (Economia aplicada). ESALQ/USP, 2000.

COSTA, S. G. Grãos na Floresta: estratégia expansionista do agronegócio na Amazônia. 2012. 322 p. Tese (Doutorado em Desenvolvimento Sustentável do Trópico Úmido) - Núcleo de Altos Estudos Amazônicos, Universidade Federal do Pará, Belém, 2012.

COSTA, S. M. G. Sojicultura e mercado de terras na Amazônia. Revista de Políticas Públicas, v. 19, n. 1, p. 173-185, 2015.

CRUZ, S. C. S. et al. Cultivo de soja sob diferentes densidades de semeadura e arranjos espaciais. Journal of Neotropical Agriculture, v. 3, n. 1, p. 1-6, 2016.

EL-HUSNY, J. C. et al. Recomendação de cultivares de soja para a microrregião de Paragominas, Pará. Embrapa Amazônia Oriental-Comunicado Técnico (INFOTECA-E), 2003.

EL-HUSNY, J. C. et al. Soja BRS Candeia: comportamento e recomendação para plantio nas microrregiões de Paragominas e Santarém, PA. Embrapa Amazônia Oriental - Comunicado Técnico (INFOTECA-E), 2006.

EMBRAPA SOJA. Tecnologias de Produção de Soja (Região Central do Brasil 2004, n. 16). Londrina, PR 2003. 245 p.

FARIAS, J. R. B.; NEPOMUCENO, A. L.; NEUMAIER, N. Ecofisiologia da soja. Embrapa Soja-Circular Técnica (INFOTECA-E), 2007.

FEARNSIDE, P. M. Deforestation in Brazilian Amazonia: History, rates, and consequences. Conservation Biology, v. 19, n. 3, p. 680-688, 2005.

FERREIRA, F. M. A importância da soja e seus derivados para a economia brasileira a partir de década de 1970. Três Rios-RJ, 2011. 46 p. Dissertação (Ciências econômicas). Unidade acadêmica de Três Rios, UFRRJ, 2011. 
FLEXOR, G. G.; LEAO, S. A. V.; LIMA, M. S. A expansão da cadeia da soja na Amazônia: os casos do Pará e Amazonas. 2006.

FREITAS, Márcio de Campos Martins de. A cultura da soja no Brasil: o crescimento da produção brasileira e o surgimento de uma nova fronteira agrícola. Enciclopédia Biosfera Centro Científico Conhecer, Goiânia-GO, v. 7, n. 12, p. 1-12, 2011.

FUKUI, T. J.; LOPES, R. L. A expansão do cultivo da soja na área de influência da BR 163 e os impactos nas regiões produtoras do estado do Paraná. Universidade Estadual de Maringá(UEM). p. 1-24 Disponível em: http://www.ecopar.ufpr.br/artigos/a4_077.pdf. Acesso em: 19 Jun 2019.

IBGE - Instituto Brasileiro de Geografia e Estatística. Produção Agrícola Municipal: área plantada, produção e produtividade de soja, 2002-2017. 2018. Disponível em: https://sidra.ibge.gov.br/tabela/5457. Acesso em: 15 Mai 2019.

KIIHL, R. A. S.; GARCIA, A. The use of the long-juvenile trai in breeding soybean cultivars. In: WORLD SOYBEAN RESERACH CONFERENCE, 4., p. 994-1000, 1989.

MACIEL, G. P.; SILVA, F. A. C.; LIMA, A. J. M.; SOUZA, M. S. P.; PEREIRA, W. C. Análise espaço-temporal da área colhida e produção de feijão-caupi (Vigna unguiculata (L.) Walp.) da microrregião do Guamá no período de 2003 a 2015. In: III Congresso Internacional das Ciências Agrárias, 3., 2018, João Pessoa-PB. Anais do Congresso Internacional das Ciências Agrárias, 2018.

MOTTA, J. L. G.; FONTANA, D. C.; WEBER, E. Evolução temporal do NDVI/NOAA em áreas cobertas por pixels com proporções variáveis de soja. Revista Brasileira de Agrometeorologia, v. 11, n. 2, p. 353-369, 2003.

NINNI, K. A floresta que virou soja. Revista Época. n. 310. 2004. Disponível em: http://revistaepoca.globo.com/Revista/Epoca/0,,EDR63939-6014,00.html. Acesso em: 07 Jun 2019.

OLIVEIRA, A. U. A Amazônia e a nova geografia da produção da soja. Terra livre, v. 1, n. 26, p. 13-43, 2015.

RODRIGUES, T. E.; VALENTE, M. A.; GAMA, J. R. N. F.; OLIVEIRA JUNIOR, R. C.; SANTOS, P. L.; SILVA, J. L. Zoneamento agroecológico do município de Paragominas, Estado do Pará. Belém: Embrapa Amazônia Oriental, 1999.

ROSA, R. Análise espacial em geografia. Revista da ANPEGE, v. 7, n. 1, p. 275 - 289, 2011.

SANCHES, A. C.; MICHELlON, E.; ROESSING, A. C. Os limites de expansão da soja. Informe GEPEC, v. 9, n. 1, 2004.

SANTOS, F. C. et al. Produtividade e aspectos nutricionais de plantas de soja cultivadas em solos de cerrado com diferentes texturas. Revista Brasileira de Ciência do Solo, v. 32, n. 5, p. 
2015-2025, 2008.

SAUER, S.; PIETRAFESA, J. P. Novas fronteiras agrícolas na Amazônia: expansão da soja como expressão das agroestratégias no Pará. ACTA geográfica, 2013. p.245-264

SCHLESINGER, S.; NORONHA, S. O Brasil está nu! O avanço da monocultura da soja: o grão que cresceu demais. Rio de Janeiro: FASE, 2006.

SILVA, M. S. et al. Composição química e valor proteico do resíduo de soja em relação ao grão de soja. Ciência e Tecnologia de Alimentos, v. 26, n. 3, p. 571-576, 2006.

SOUSA, I. S. F. Condicionantes da modernização da soja no Brasil. Revista de Economia e Sociologia Rural, v.28, n.2, p.175-212, abr./jun. 1990.

SOUZA, V. C. O.; VIEIRA, T. G. C.; ALVES, H. M. R.; VOLPATO, M. M. L. Análise espaçotemporal da cafeicultura mineira: 1990-2009. In: VI Simpósio de Pesquisa dos Cafés do Brasil, 2009, Vitória. Anais do Simpósio de Pesquisa dos Cafés do Brasil, 2009.

TANAKA, R. T.; MASCARENHAS, H. A. A; BORKET, C. M. Nutrição mineral da soja. In: ARANTES, N. E.; SOUZA, P. I. M. Cultura de soja nos cerrados. Piracicaba: Potafos, 1993. 535p. 